\title{
Morus rubra Extract Induces G Cell Cycle Arrest and Apoptosis in Human Lung and Prostate Cancer Cells
}

\author{
Ibrahim Turan ${ }^{1,2}$, Selim Demir ${ }^{3 *}$, Kagan Kilinc ${ }^{1}$, Yuksel Aliyazicioglu ${ }^{4}$, Ahmet Alver ${ }^{4}$, Sema Misir $^{4,5}$, \\ Serap Ozer Yaman ${ }^{4}$, Kubra Akbulut ${ }^{4}$, Ahmet Mentese ${ }^{6}$, Orhan Deger ${ }^{4}$
}

1Department of Genetic and Bioengineering, Faculty of Engineering and Natural Sciences, Gumushane University, 29100, Gumushane, ${ }^{2}$ Medicinal Plants, Traditional Medicine Practice and Research Center, Gumushane University, 29100, Gumushane, ${ }^{3}$ Department of Nutrition and Dietetics, Faculty of Health Sciences, Karadeniz Technical University, 61080, Trabzon, ${ }^{4}$ Department of Medical Biochemistry, Faculty of Medicine, Karadeniz Technical University, 61080, Trabzon, ${ }^{5}$ Department of Biochemistry, Faculty of Pharmacy, Cumhuriyet University, 58140, Sivas,

${ }^{6}$ Program of Medical Laboratory Techniques, Vocational School of Health Sciences, Karadeniz Technical University, 61080, Trabzon, Turkey.

\begin{abstract}
Objective: Cancer is one of the most deadly types of disease and evasion from apoptosis and unstoppable cell proliferation are accepted as its distinctive features. Many studies have evaluated the cytotoxic effect of different Morus species but, there is no study about cytotoxic effect of Morus rubra. In this study we aimed to evaluate phenolic composition, antioxidant properties and cytotoxic effect of acidified dimethyl sulfoxide extract of $M$. rubra (AMRE). Method: Antioxidant properties, phenolic composition and cytotoxic effect of AMRE were determined using spectrophotometric methods, HPLC, and MTT assay, respectively. Then, mechanisms of cytotoxic effect of AMRE on human prostate (PC-3) and lung (A549) cancer cells were examined in regard to cell cycle, apoptosis and mitochondrial membrane potential using flow cytometric methods. Results: Total phenolic content and reducing power values were $11.9 \mathrm{mg}$ gallic acid equivalents and $42.9 \mathrm{mg}$ trolox equivalents per g sample, respectively. Ascorbic and gallic acid were detected in AMRE as major antioxidant compounds. We determined that AMRE increased cell cycle arrest at $\mathrm{G}_{1}$ phase and exhibited apoptotic features via decreasing mitochondrial membrane potential in both prostate and lung cancer cells. Conclusion: These findings demonstrate that $M$. rubra extract can affect the behavior of human prostate and lung cancer cells in vitro conditions, and this effect now needs to be investigated in vivo.
\end{abstract}

Key words: Apoptosis, Cell Cycle, Cytotoxicity, Lung Neoplasms, Morus rubra, Prostate Neoplasms.

\section{INTRODUCTION}

Morus rubra, known as "red mulberry" belongs to the family Moraceae and the genus Morus. Mulberries are unique to temperate regions of Asia, Europe and North America. ${ }^{1,2}$ In folk medicines, fruits of Morus species are used to treat fever, hypertension, arthritis, anemia, oral and liver diseases. The dark-colored Morus fruits are rich source of phenolic compounds, containing anthocyanins and carotenoids. It has found that mulberry fruit extracts exhibit antioxidant, antimicrobial and anti-inflammatory properties as these activities are due to the above mentioned compounds. ${ }^{3}$

Cancer is one of the most deadly types of disease and evasion from apoptosis and unstoppable cell proliferation are accepted as its distinctive features. ${ }^{4}$ Prostate and lung cancer which are the most common cancer types and are the leading cause of cancer related death worldwide., ${ }^{4,5}$ Chemotherapy is frequently used against these cancers but, the major deficiencies of chemotherapeutic agents are systemic toxicity and drug resistance over time. To solve these
Submission Date: 22-08-2016; Revision Date: 26-09-2016; Accepted Date: 28-09-2016

DOI: 10.5530/ijper.51.1.8 Correspondence: Selim Demir, PhD, Assistant Professor, Department of Nutrition and Dietetics, Faculty of Health Sciences, Karadeniz Technical University, 61080, Trabzon, Turkey.

Telephone number: +90462 37788 41; Fax number: +90 4623252821

E-mail: selim-demir@ hotmail.com

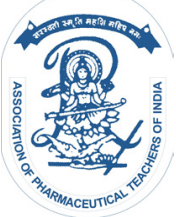

www.ijper.org 
problems, scientific community enter new search for exploration of efficient chemotherapeutics and natural products are accepted as novel candidate for development new chemotherapeutics due their high anticancer activity and less toxicity in normal cells. ${ }^{6,7}$

There are many studies about cytotoxic effect of different berry species. Seeram et al reported that fresh fruit extracts of various berries have cytotoxic effects on human oral, breast, prostate and colon cancer cells, ${ }^{8}$ while Naowaratwattana et al demonstrated that $M$. alba leaf extract inhibits the proliferation of HepG2 cells in a dose-dependent manner by inducing cell cycle arrest at $\mathrm{G}_{2} / \mathrm{M}$ phase, caspase activity and inhibiting topoisomerase II $\alpha$ activity. ${ }^{9}$ Recently, Deepa et al demonstrated that M. alba extract induces apoptosis in HCT-15 and MCF-7 cells and downregulation of inducible nitric oxide synthase is suggested as a possible apoptotic mechanism. ${ }^{10}$ However, to the authors' best knowledge there is no study reporting cytotoxic effect of M. rubra in the literature. Therefore, the objective of the current study was to determine chemical composition and antioxidant properties of acidified dimethyl sulfoxide extract of M. rubra (AMRE) and farther to search the probable cytotoxic effect in human prostate and lung adenocarcinoma cells coupled with mechanism of action for the first time.

\section{MATERIALS AND METHODS}

\section{Chemicals and Reagents}

Kaighn's modification of Ham's F-12 (F-12K) and Eagle's minimal essential medium (EMEM) media were purchased from Lonza (Verviers, Belgium). Fetal bovine serum (FBS) was from Biochrom (Berlin, Germany). Penicillin-streptomycin and trypsin-EDTA solution from Biological Industries (Kibbutz Beit Haemek, Israel). All flow cytometric kits (DNA reagent, FITC Annexin $\mathrm{V}$ apoptosis detection and mitochondrial membrane potential detection kits) were purchased from BD Biosciences (San Diego, CA, USA). The other principal chemicals used were obtained from Sigma (St. Louis, MO, USA).

\section{Plant Collection and Extraction}

Fully mature fruits of $M$. rubra were harvested from Gumushane, Turkey. The fruits were air-dried at room temperature and powdered using blender and milling into fine powder. The fruit powder $(1 \mathrm{~g})$ was extracted with $20 \mathrm{~mL}$ dimethyl sulfoxide (DMSO) plus $0.5 \%$ hydrochloric acid in a mechanical shaker (Shell Lab, Cornelius, OR, USA) in the dark for $24 \mathrm{~h}$ at $45^{\circ} \mathrm{C}$. The prepared $50 \mathrm{mg} / \mathrm{mL}$ stock AMRE was filtered with
Whatman No. 1 filter paper and $0.2 \mu \mathrm{m}$ filter and then stored at $-20^{\circ} \mathrm{C}$ until used for further experiments.

\section{Drug Preparation and Treatment}

Cisplatin which was used as a reference chemotherapeutic drug for cytotoxicity studies due to its use in prostate and lung cancer treatments ${ }^{11,12}$ and was dissolved in DMSO. External working concentrations of both extract and cisplatin were prepared by further dilution with their solvents. The final concentration of solvents was never higher than $0.5 \%$ in culture media. Under these conditions, solvents were not toxic for studied cells.

\section{Estimation of Total Phenolic Content (TPC)}

Content of total polyphenols of AMRE was established with Folin-Ciocalteau procedure ${ }^{13}$ adapted to microscale using gallic acid as the standard. The results were calculated as $\mathrm{mg}$ of gallic acid equivalent (GAE) per g sample using a standard graph.

\section{Estimation of Reducing Power}

The reducing power of AMRE was established using the method described previously ${ }^{14}$ adapted to microscale using trolox as the standard. The results were calculated as $\mathrm{mg}$ of trolox equivalent (TE) per g sample using a standard graph.

\section{HPLC Analysis of Phenolic Compounds}

Nine standards were used for HPLC analysis: ascorbic acid, gallic acid, 3,4-dihydroxy benzoic acid, protocatechuic acid, chlorogenic acid, caffeic acid, epigallocatechin gallate, $p$-coumaric acid, and rutin hydrate. The propylparaben was used as an internal standard. ${ }^{15}$ The analysis was performed by reversed phase HPLC on a Agilent Infinity 1200 (CA, USA) liquid chromatograph equipped with a diode array detector (DAD). The chromatographic separation was performed on a $5 \mu \mathrm{m}(150 \times 4.6$ $\mathrm{mm}$ i.d.) reversed-phase $\mathrm{C}_{18}$ column (Macherey-Nagel, Duren, Germany). The solvent system used was a gradient of solvent A ( $2 \%$ acetic acid in water), and solvent B $(0.5 \%$ acetic acid in acetonitrile:water (1:1)). Flow rate and injection volume were $0.8 \mathrm{~mL} / \mathrm{min}$ and $10 \mu \mathrm{L}$, respectively. ${ }^{16}$ Signals were detected at 240,254 , 260, 270, 275, 280, 300 and $324 \mathrm{~mm}$ by DAD. Identification of compounds was performed comparing retention times and spectral data with those of pure standards. Calibration curves of the standards were used for quantitation.

\section{Cell Culture}


Human prostate (PC-3, CRL-1435), lung (A549, CCL-185) cancer cells and human normal foreskin fibroblast (CRL-2522) cells were purchased from the American. Type Culture Collection (Manassas, VA, USA). PC-3 and A549 cells were propagated in F-12K, fibroblast cells were propagated in EMEM, supplemented 10\% FBS, $1 \%$ penicillin and streptomycin at $37^{\circ} \mathrm{C}$ with $5 \% \mathrm{CO}_{2}$.

\section{Cytotoxicity Assay}

The cytotoxicity of the extract and cisplatin were determined using the MTT assay, ${ }^{17}$ which is a tetrazolium salt and is reduced to purple formazan crystals by metabolically active cells. ${ }^{18}$ Briefly, the cells were seeded into a 96-well plate $\left(5 \times 10^{3}\right.$ cells per well $)$ and treated with several concentrations of AMRE $(0-500 \mu \mathrm{g} / \mathrm{mL})$ and cisplatin $(0-10 \mu \mathrm{g} / \mathrm{mL})$ for $72 \mathrm{~h}$. After the incubation time, $10 \mu \mathrm{L}$ of MTT dye $(0.25 \mathrm{mg} / \mathrm{mL})$ was added to the wells and the composed crystals were then dissolved in DMSO. The absorbance was detected at $570 \mathrm{~nm}$ using a microplate reader (Molecular Devices, CA, USA) and optical densities were used to determine $\%$ cell viabilities. The antiproliferative potential of AMRE and cisplatin were expressed as $\mathrm{IC}_{50}$ values. ${ }^{19}$ Following the cytotoxicity experiments, calculated $\mathrm{IC}_{50}$ and $\mathrm{IC}_{90}$ concentrations of AMRE were used in flow cytometric studies.

\section{Flow Cytometry Analysis for Cell Cycle Distribution}

A549 and PC-3 cells in exponential phase of growth were treated with $\mathrm{IC}_{50}$ and $\mathrm{IC}_{90}$ concentrations of AMRE for $72 \mathrm{~h}$, then harvested by trypsinization, and washed 2 times with buffer solution (contains sodium citrate, sucrose, and DMSO). $250 \mu \mathrm{L}$ of solution A (trypsin buffer) was added to each tube and incubated for $10 \mathrm{~min}$ at room temperature. Then, $200 \mu \mathrm{L}$ of solution B (trypsin inhibitor and RNase buffer) was added to each tube and incubated for $10 \mathrm{~min}$ at room temperature. Finally, $200 \mu \mathrm{L}$ of cold solution C (PI stain solution) was added to each tube and incubated for $10 \mathrm{~min}$ in the dark on ice. Data from 30000 cells per sample were collected and analyzed on a flow cytometer (FACSCalibur, Becton Dickinson, East Rutherford, NJ, USA).

\section{Measurement of Apoptosis by Flow Cytometry}

A549 and PC-3 cells in exponential phase of growth were treated with $\mathrm{IC}_{50}$ and $\mathrm{IC}_{90}$ concentrations of AMRE for $72 \mathrm{~h}$, then harvested by trypsinization, and washed 2 times with ice-cold phosphate buffered saline (PBS). Then, the cells were resuspended with $100 \mu \mathrm{L}$ of the binding buffer. $5 \mu \mathrm{L}$ of FITC Annexin V and 5 $\mu \mathrm{L}$ PI was added to each tube and incubated for $10 \mathrm{~min}$ at room temperature in the dark. Finally, $400 \mu \mathrm{L}$ of the binding buffer was added to each tube and data from
10000 cells per sample were collected and analyzed on a flow cytometer within $1 \mathrm{~h}$.

\section{Measurement of Mitochondrial Transmembrane Potential}

Mitochondrial transmembrane potential was evaluated by using JC-1 probe. Mitochondrial transmembrane potential depolarization is specifically indicated by a decrease in the red-to-green fluorescence intensity ratio. ${ }^{19}$

Cells were treated with $\mathrm{IC}_{50}$ and $\mathrm{IC}_{90}$ concentrations of AMRE for $72 \mathrm{~h}$, then harvested by trypsinization, and washed 2 times with ice-cold PBS. $500 \mu \mathrm{L}$ of the freshly prepared JC-1 working solution was added to each tubes and incubated for $15 \mathrm{~min}$ at $37^{\circ} \mathrm{C}$ in a $\mathrm{CO}_{2}$ incubator. Then, cells were washed 2 times with assay buffer and finally, each cell pellet was gently resuspended in $500 \mu \mathrm{L}$ of assay buffer. Data from 10000 cells per sample were collected and analyzed on a flow cytometer. The results were stated as relative mitochondrial membrane potential compared to untreated cells.

\section{Statistical Analysis}

Data are from at least three independent experiments and expressed as means \pm SD. Statistical evaluation of the data was performed using ANOVA, followed by post-hoc Tukey's tests. A p value less than 0.05 was considered significant.

\section{RESULTS}

Total polyphenolic content and reducing power values of AMRE were $11.9 \pm 0.1 \mathrm{mg}$ GAE and $42.9 \pm 1.6 \mathrm{mg}$ TE per g sample, respectively.

The chromatogram of standards is shown in Figure 1. The compounds in M. rubra are shown in Table 1 and the values were stated in $\mu \mathrm{g} / \mathrm{g}$ sample. Ascorbic acid and gallic acid were the most abundant compounds in

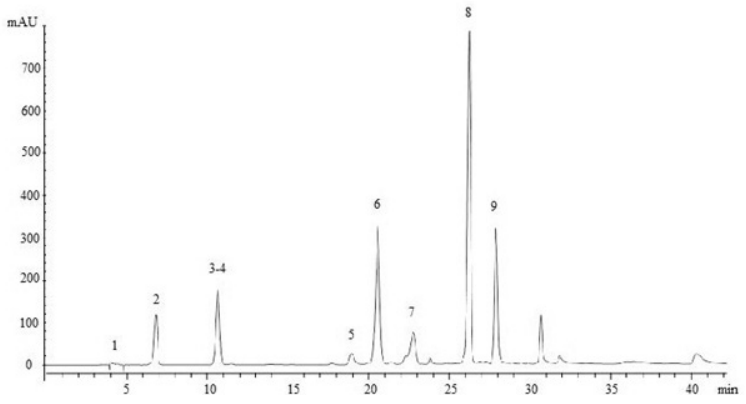

Figure 1: HPLC chromatogram of phenolic standards (at 280 $\mathrm{nm})$. Numbers above each peak correspond to respective standards: ascorbic acid (1), gallic acid (2), 3,4-dihydroxy benzoic acid (3), protocatechuic acid (4), chlorogenic acid (5), caffeic acid (6), epigallocatechin gallate (7), p-coumaric acid (8), and rutin hydrate (9). 


\begin{tabular}{|c|c|c|}
\hline \multicolumn{2}{|c|}{ Table 1: Phenolic compounds identified in acidified $\boldsymbol{M}$. rubra extract by HPLC-DAD } \\
\hline Phenolic compounds & Retention time $(\mathbf{m i n})$ & Amount $(\boldsymbol{\mu g} / \mathbf{g}$ sample) \\
\hline Ascorbic acid & 3.99 & $177.2 \pm 7.1$ \\
\hline Gallic acid & 6.80 & $552.8 \pm 30.4$ \\
\hline 3,4-dihydroxy benzoic acid & 10.65 & $37.1 \pm 1.6$ \\
\hline Protocatechuic acid & 10.65 & $52.2 \pm 2.5$ \\
\hline Chlorogenic acid & 18.95 & $74.1 \pm 3.3$ \\
\hline Caffeic acid & 20.56 & ND \\
\hline Epigallocatechin gallate & 22.28 & $133.7 \pm 7.8$ \\
\hline p-coumaric acid & 26.23 & ND \\
\hline Rutin hydrate & 27.88 & $9.0 \pm 0.3$ \\
\hline
\end{tabular}

Notes: Mean value of three determinations (three replicates) \pm SD. ND, not detected.

Table 2: Cytotoxic activity $\left(\mathrm{IC}_{50}, \mu \mathrm{g} / \mathrm{mL}\right)^{*}$ of AMRE and cisplatin $(\mathrm{n}=4)$

\begin{tabular}{|c|c|c|c|}
\hline Test Compounds & \multicolumn{3}{|c|}{ Cell Line } \\
\hline & A549 & PC-3 & Fibroblast \\
\hline AMRE & $288.5 \pm 4.7$ & $360.0 \pm 8.4$ & $449.5 \pm 12$ \\
\hline Cisplatin & $0.715 \pm 0.03$ & $0.597 \pm 0.04$ & $4.87 \pm 0.16$ \\
\hline
\end{tabular}

*IC ${ }_{50}$ is defined as the concentration inhibiting $50 \%$ of cell growth (viability) after the treatment with AMRE and cisplatin for $72 \mathrm{~h}$, according to the MTT assay.

M. rubra (Table 1). The small peak of ascorbic acid in Figure 1 (at $280 \mathrm{~nm}$ ) is due its maximum wavelength is $240 \mathrm{~nm} .3$,4-dihydroxy benzoic acid and protocatechuic acid had same retention time and DAD spectrum in our study. We therefore determined separately their quantities according to their calibration curves.

All cells were treated with various concentrations of AMRE and cisplatin for $72 \mathrm{~h}$ and their effects on cell growth were determined by MT'T assay. The $\mathrm{IC}_{50}$ values for tested compounds are presented in Table 2. AMRE exhibited moderate selective cytotoxicity against both PC-3 and A549 cells compared to foreskin fibroblast cells.

The results of the cell cycle analysis of PC-3 cells are presented in Figure 2A. Both concentrations (360 and $648 \mu \mathrm{g} / \mathrm{mL}$ ) of AMRE significantly increased the cell numbers at the $G_{0} / G_{1}$ phase $(p=0.001$ and $p=0.0001$, respectively) in PC-3 cells. Besides, both concentrations of AMRE significantly decreased cell numbers at the $\mathrm{S}$ phase $(\mathrm{p}=0.0001)$. The results of the cell cycle analysis of A549 cells are presented in Figure 2B. Both concentrations $(290$ and $520 \mu \mathrm{g} / \mathrm{mL}$ ) of AMRE significantly increased the cell numbers at the $G_{0} / G_{1}$ phase $(p=0.004$ and $\mathrm{p}=0.001$, respectively) in A549 cells.

The results of the Annexin V analysis of PC-3 cells are presented in Figure 3A. The concentrations of $360 \mu \mathrm{g} / \mathrm{mL}$ of AMRE increased the number of necrotic, late and early apoptotic cells, but this differences were not significant ( $p>0.05)$. However, the concentrations of 648 $\mu \mathrm{g} / \mathrm{mL}$ of AMRE significantly reduced the number of survival cells and increased the number of necrotic, late and early apoptotic cells $(p=0.001)$. The results of the Annexin V analysis of A549 cells are presented in Figure 3B. Both concentrations (290 and $520 \mu \mathrm{g} / \mathrm{mL}$ ) of AMRE significantly increased the number of late apoptotic cells $(\mathrm{p}=0.001$ ), while only the concentration of $520 \mu \mathrm{g} / \mathrm{mL}$ of AMRE extract significantly increased the number of early apoptotic cells $(\mathrm{p}=0.043)$.

Mitochondrial membrane potential analysis results of PC-3 and A549 cells are presented in Figure 4. Only the highest concentrations of AMRE significantly reduced mitochondrial membrane potential in PC-3 and A549 cells $(\mathrm{p}=0.0001)$. The percentage reductions in mitochondrial membrane potential by AMRE were $70.9 \%$ and $32.1 \%$ for concentrations of 648 and $520 \mu \mathrm{g} / \mathrm{mL}$ for PC-3 and A549 cells, respectively.

\section{DISCUSSION}

Cancer is one of the most important malignant disease and chemotherapy is often used its treatment, but it can cause some side effects, such as increased drug resistance in cancer cells and harmful effect in healthy cells over time. ${ }^{20}$ Thus, new approaches are needed to solve these problems, and natural products are accepted possible candidates for exploration of new anticancer agents due their high anticancer activity in cancer cells and less toxicity in normal cells. ${ }^{7}$ Plants are excellent source of foods, chemicals and herbal medicines. Many important drugs have been derived from them. ${ }^{21}$ M. rubra is one of the most important species of the genus Morus, with fruits having substantial levels of 

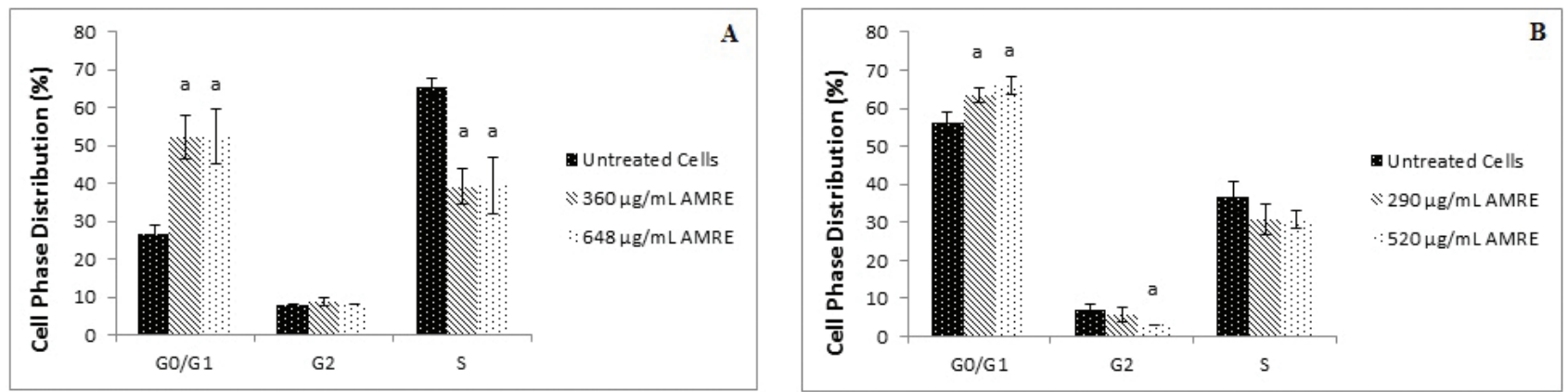

Figure 2: Cell cycle analysis of PC-3 (A) and A549 (B) cells treated for $72 \mathrm{~h}$ with AMRE at different concentrations. ${ }^{a}$ Represents significant results $(p<0.05)$ compared with untreated cells.
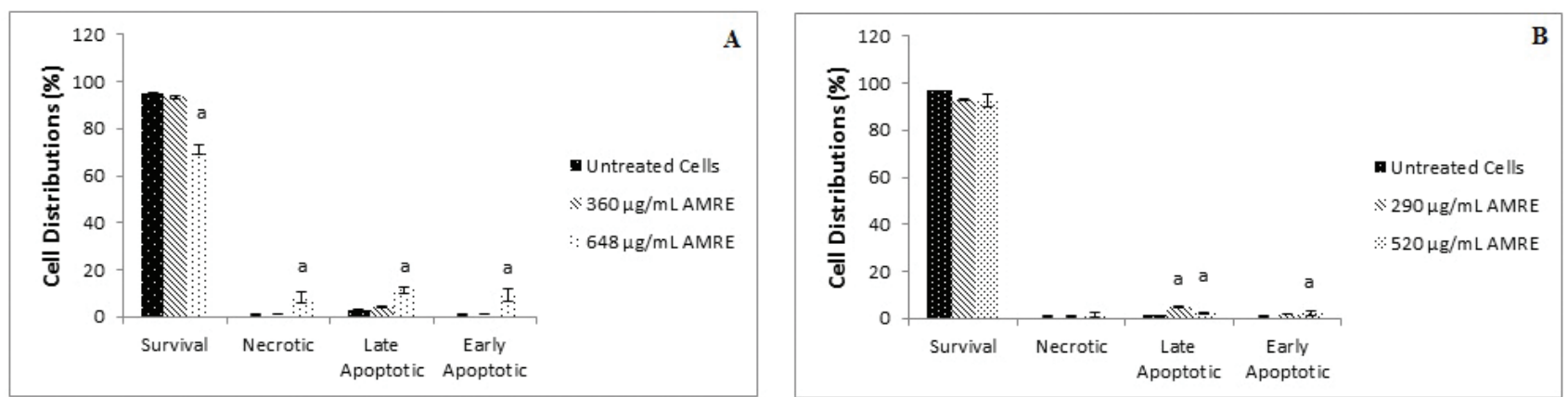

Figure 3: Apoptosis analysis of PC-3 (A) and A549 (B) cells treated with different concentrations of AMRE for 72

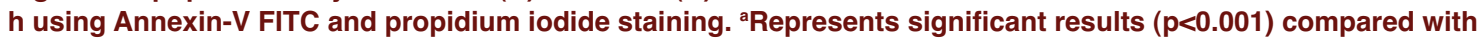
untreated cells.
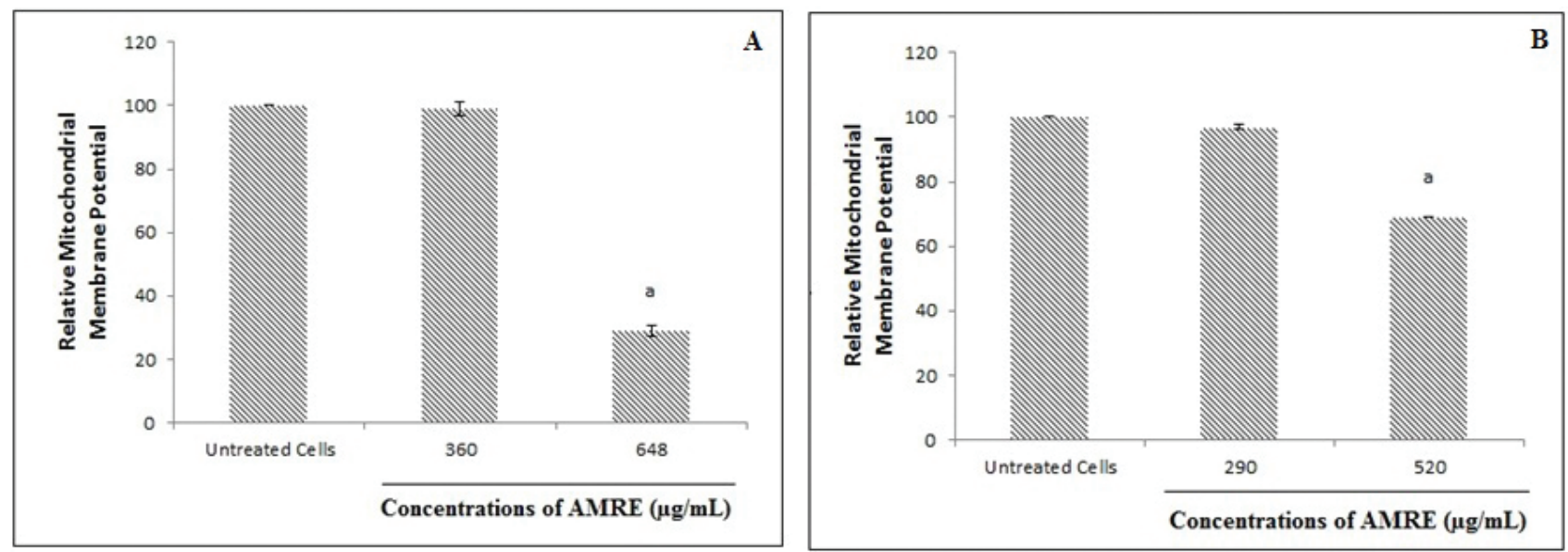

Figure 4: JC-1 staining for AMRE-induced dissipation of mitochondrial membrane potential in PC-3 (A) and A549 (B) cells. ${ }^{a}$ Represents significant results $(p<0.05)$ compared with untreated cells.

phenolics, anthocyanins, carotenoids and ascorbic acid. ${ }^{3}$ Many studies have investigated the cytotoxic effects of different berry species, ${ }^{8-10}$ however to the authors' best knowledge there is no study reporting cytotoxic effect of $M$. rubra in the literature. It is adviced that in vitro experiments are helpful and advisor for determining first biological effect of a natural or syntetic product. If favourable data are attained from these experiments, then clinical studies are adviced. ${ }^{22}$ Prostate and lung cancer are the most common cancer types worldwide and the PC-3 and A549 cell lines are used frequently as in vitro prostate and lung cancer model. ${ }^{19,23-25}$ We therefore, planned this study on the A549 and PC-3 cancer cell lines under in vitro conditions.

Many in vitro assay are used for determination of antioxidant activity of herbal extracts and at least using two different methods are recommended. ${ }^{26}$ The TPC and reducing power assay were therefore preferred for evaluation of antioxidant activity of AMRE in this study. TPC and FRAP values of AMRE were $11.9 \pm 0.1 \mathrm{mg}$ GAE and $42.9 \pm 1.6 \mathrm{mg}$ TE per $\mathrm{g}$ sample, respectively. The TPC values of different extracts of $M$. rubra fruit 
from Turkey range between 1.6 and $10.4 \mathrm{mg} \mathrm{GAE} / \mathrm{g}$ sample (reviewed in Ref 27). Dimitrova et al reported that TPC and FRAP values of $70 \%$ ethanol extract of M. rubra from Bulgaria are $0.9 \mathrm{mg}$ GAE and $1.8 \mathrm{mM}$ TE per $g$ sample, respectively. ${ }^{28}$ It is reported that M. rubra fruits are rich in phenolic compounds, such as quercetin, kaempferol, rutin, catechin, chlorogenic acid, p-coumaric acid, o-coumaric acid, vanillic acid, gallic acid, caffeic acid, and caffeoylquinnic acid (reviewed in Ref 27). Gundogdu et al reported that M. rubra from Van (in Turkey) are rich in gallic acid, catechin, chlorogenic acid, caffeic acid, syringic acid, $p$-coumaric acid, ferulic acid, o-coumaric acid, phloridzin, protocatechuic acid, vanilic acid, rutin, and quercetin. Rutin and chlorogenic acid are most abundant phenolics in this study. ${ }^{3}$ We determined that seven compounds were in AMRE and gallic acid was the most abundant compound. There was not a fully overlapping between our phenolic composition results and literature data. This situation may have arisen from the plant species and number and kind of used standards. We think that the phenolic composition of $M$. rubra might reveal with further standard compounds in the future investigations.

Some criterias, such as high effectiveness against multiple cancer cells and innocuous impacts on healthy cells, are determined for an effective chemopreventive agent. ${ }^{29}$ Thus, we carried out cytotoxicity studies in two cancer cells coupled with foreskin fibroblast cells as a normal cell line. We confirmed that only AMRE exhibited reasonable selective toxicity against A549 and PC-3 cells compared to normal fibroblast cells by MTT assay, which is a widely used method in cytotoxicity studies. ${ }^{18,19}$ There are many studies about cytotoxic affects of different berry species in the literature. It is reported that $80 \%$ acetone extracts of various raspberry (fresh heritage, kiwigold, goldie, and anne) have cytotoxic effect in human hepatocellular cancer (HepG2) cells, ${ }^{30}$ while Seeram et al demonstrated that fresh fruit extracts of various berries have cytotoxic effects on human oral, breast, prostate and colon cancer cells. Especially, black raspberry and strawberry extracts exhibit apoptotic feaures in colon cancer cells for $48 \mathrm{~h}$ treatment. ${ }^{8}$ Also, Skupien et al reported that $M$. alba leaf extract has cytotoxic effect both human leukaemic cell line (HL60) and its multidrug resistant sublines. ${ }^{31}$ Some researches now focus on the bioactive components of mulberry and concordantly Dat et al reported 11 flavonoids from the methanol extract of $M$. alba leaves, which were cytotoxic to HeLa, MCF-7, and Hep3B cancer cells. ${ }^{32}$ Interestingly, synergistic cytotoxic effect of a natural compound may not observed when its purified polyphenolic compounds were used. ${ }^{33}$ We therefore think that the mecha- nism of cytotoxic activity of AMRE may be explained with synergistic effects of all constituents of extract.

Mammalian cell proliferation are occured via cell cycle progression, and defects in cell cycle are one of the most common features of cancer cells. Thus, cell cycle arrest is approved one of the target mechanisms for cancer therapy. ${ }^{34}$ Nguyen et al showed that bilberry extract inhibits human breast cancer cell proliferation in a dosedependent manner in concert with induction of apoptotic cell death but no effect is observed on cell cycle in lowest concentrations. Hovewer, higher extract concentrations which cause an arrest of cells at the $G_{2} / M$ phase of the cell cycle and modify microtubule organization, ${ }^{35}$ while Naowaratwattana et al reported that $M$. alba leaf extract inhibits the proliferation of HepG2 cells in a dose-dependent manner by inducing cell cycle arrest at $\mathrm{G}_{2} / \mathrm{M}$ phase, caspase activity and inhibiting topoisomerase II $\alpha$ activity. ${ }^{9}$ Recently, Kollar et al reported that prenylated flavonoids from Morus alba inhibit the growth of human monocytic leukemia (THP-1) cells through inducing $G_{1}$ cell cycle arrest and apoptotic pathway. ${ }^{36}$ We determined that AMRE induced cell cycle arrest at $\mathrm{G}_{0} / \mathrm{G}_{1}$ phase in both A549 and PC-3 cells in a concentration dependent manner. Our results as soon as were similar with previous studies, the differences may have originated from the plant species, type of extraction method and solvent, cell type and cell line specificity.

Suppression of apoptosis during carcinogenesis is known to play a role in the development of cancers and induction of apoptosis could be therefore an ideal target for the therapy of many cancer cells. ${ }^{37}$ When cells are undergoing apoptosis, phosphatidylserine (PS), which makes up a portion of the cell membrane, will translocate towards the extracellular side of the membrane. Annexin V, a 35-36 kDa phospholipid-binding protein, has a high affinity for PS. The translocation of PS to the outside or exposed side of the membrane is an early event in the apoptotic process; therefore, Annexin V staining is considered a marker for early stage apoptosis. ${ }^{38}$ Mitochondria are essential organel for both vital (energy production) and lethal (apoptosis) functions in physiological and pathological scenarios and decreased mitochondrial membrane potential could caused to apoptotic cell death in cells. ${ }^{39}$ Lee et al demonstrated that morusin which is isolated from root bark of Morus australis and inhibits growth of human colon cancer cells via activation of caspases and inhibition of NF- $x \mathrm{~B}$ pathway, ${ }^{40}$ while Faria et al reported that blueberry anthocyanin-pyruvic acid adduct extract exhibits cytotoxic effect on human breast cancer cells via caspase activation. ${ }^{41}$ In another study, albanol A from the root bark induces apoptosis in leukemia cells, ${ }^{42}$ whereas 
Deepa et al demonstrated that $M$. alba extract induces apoptosis in HCT-15 and MCF-7 cells and downregulation of inducible nitric oxide synthase is suggested as a possible apoptotic machanism. ${ }^{10}$ Our results show that acidified M. rubra extract exhibited apoptotic features on both A549 and PC-3 cells by reducing mitochondrial membrane potential.

Studies have suggested that the anticancer characteristics of phenolic compounds derive from pro-oxidant, rather than antioxidant activities. Such pro-oxidant activity is related to the cell's redox status. Higher basal redox levels have been determined in cancer cells then in normal cells as a result of their higher levels of free heavy metal ions and more elevated metabolic rate. ${ }^{19}$ Mounting evidence suggests that increasing oxidative stress by polyphenols in cancer cells may be an effective strategy for eliminating these cancer cells. ${ }^{43}$ Jeong et al reported that mulberry fruit extracts have cytotoxic effect on human glioma cells through reactive oxygen species (ROS) dependent mitochondrial pathway and induction of apoptosis. ${ }^{44}$ We therefore speculate that the antiproliferative effect of $M$. rubra extract in studied cancer cells may derive from its capacity to form ROS due to its polyphenolic components.

\section{CONCLUSION}

This study is the first to investigate the effect of pro-apoptotic and antiproliferative properties of M. rubra extract on prostate and lung cancer cells. One limitation of this research is that in vitro studies cannot be extrapolated to possible activity in vivo. Further studies are now necessary to understand in more detail the exact interaction of the involved signaling pathways.

\section{ACKNOWLEDGMENTS}

The authors wish to thank Professor Mehmet Sonmez from the Karadeniz Technical University Hematology Department for professional assistance with the flow cytometry studies.

\section{CONFLICTS OF INTEREST STATEMENT}

None of the authors had any financial or personal relationships with other individuals or organizations that might inappropriately influence their work during the submission process.

\section{REFERENCES}

1. Ercisli S, Orhan E. Chemical composition of white (Morus alba), red (Morus rubra) and black (Morus nigra) mulberry fruits. Food Chem. 2007;103(4):1380-4.
2. Thabti I, Elfalleh W, Hannachi H, Ferchichi A, Da Graca Campos M. Identification and quantification of phenolic acids and flavonol glycosides in Tunisian Morus species by HPLC-DAD and HPLC-MS. J Funct Foods. 2012;4(1):367-74.

3. Gundogdu M, Muradoglu F, Gazioglu S RI, Yilmaz H. Determination of fruit chemical properties of Morus nigra L., Morus alba L. and Morus rubra L. by HPLC. Sci Hort. 2011;132:37-41.

4. Ouyang L, Luo Y, Tian M, Zhang SY, Lu R, Wang JH, et al. Plant natural products: From traditional compounds to new emerging drugs in cancer therapy. Cell Prolif. 2014;47(6):506-15.

5. Liu KC, Huang AC, Wu PP, Lin HY, Chueh FS, Yang JS, et al. Gallic acid suppresses the migration and invasion of $\mathrm{PC}-3$ human prostate cancer cells via inhibition of matrix metalloproteinase-2 and -9 signaling pathways. Oncol Rep. 2011;26(1):177-84.

6. Chen PN, Chu SC, Chiou HL, Chiang CL, Yang SF, Hsieh YS. Cyanidin 3-glucoside and peonidin 3-glucoside inhibit tumor cell growth and induce apoptosis in vitro and suppress tumor growth in vivo. Nutr Cancer. 2005;53(2):232-43.

7. Fulda S. Modulation of apoptosis by natural products for cancer therapy. Planta Med. 2010;76(11): 1075-9.

8. Seeram NP, Adams LS, Zhang Y, Lee R, Sand D, Scheuller HS, et al. Blackberry, black raspberry, blueberry, cranberry, red raspberry, and strawberry extracts inhibit growth and stimulate apoptosis of human cancer cells in vitro. J Agric Food Chem. 2006;54(25):9329-39.

9. Naowaratwattana W, De-Eknamkul W, De Mejia EG. Phenolic-containing organic extracts of mulberry (Morus alba L.) leaves inhibit HepG2 hepatoma cells through $\mathrm{G}_{2} / \mathrm{M}$ phase arrest, induction of apoptosis, and inhibition of topoisomerase Ila activity. J Med Food. 2010;13(5):1045-56.

10. Deepa M, Sureshkumar T, Satheeshkumar PK, Priya S. Antioxidant rich Morus alba leaf extract induces apoptosis in human colon and breast cancer cells by the downregulation of nitric oxide produced by inducible nitric oxide synthase. Nutr Cancer. 2013;65(2):305-10.

11. Puglisi M, Dolly S, Faria A, Myerson JS, Popat S, O'Brien MER. Treatment options for small cell lung cancer - do we have more choice?. Br J Cancer. 2010;102(4):629-38.

12. Dhar S, Kolishetti N, Lippard SJ, Farokhzad OC. Targeted delivery of a cisplatin prodrug for safer and more effective prostate cancer therapy in vivo. PNAS. 2011;108(5):1850-5.

13. Slinkard K, Singleton VL. Total phenol analyses: automation and comparison with manual methods. Am J Enol Viticult. 1977;28(1):49-55.

14. Oyaizu M. Studies on products of browning reactions: antioxidative activities of products of browning reaction prepared from glucosamine. Jpn J Nutr. 1986;44:307-15.

15. Ozturk N, Tuncel M, Tuncel NB. Determination of phenolic acids by a modified HPLC: Its application to various plant materials. J Liq Chromatogr Related Technol. 2007;30(4):587-96.

16. De Villiers A, Lynen F, Crouch A, Sandra P. Development of a solid-phase extraction procedure for the simultaneous determination of polyphenols, organic acids and sugars in wine. Chromatographia. 2004;59(7-8):403-9.

17. Mosmann T. Rapid colorimetric assay for cellular growth and survival: Application to proliferation and cytotoxicity assays. J Immunol Methods. 1983;65(1-2):55-63.

18. Russo A, Cardile V, Sanchez F, Troncoso N, Vanella A, Garbarino JA. Chilean propolis: antioxidant activity and antiproliferative action in human tumor cell lines. Life Sci. 2004;76(5):545-58.

19. Demir S, Aliyazicioglu Y, Turan I, Misir S, Mentese A, Yaman SO, et al. Antiproliferative and proapoptotic activity of Turkish propolis on human lung cancer cell line. Nutr Cancer 2016;68(1):165-72.

20. UrruticoecheaA, Alemany R, Balart J, Villanueva A, Vinals F, Capella G. Recent advances in cancer therapy: an overview. Curr Pharm Des. 2010;16(1):3-10.

21. Khalid N, Fawad SA, Ahmed I. Antimicrobial activity, phytochemical profile and trace minerals of black mulberry (Morus nigra L.) fresh juice. Pak J Bot. 2011;43:91-6.

22. Sforcin JM, Bankova V. Propolis: is there a potential for the development of new drugs? J Ethnopharmacol. 2011;133(2):253-60.

23. Shahneh FZ, Baradaran B, Majidi J, Babaloo Z. Echinophora platyloba DC (Apiaceae) crude extract induces apoptosis in human prostate adenocarcinoma cells (PC-3). Biomed J. 2014;37(5):298-304. 
24. Huo C, Kao YH, Chuu CP. Androgen receptor inhibits epithelial-mesenchymal transition, migration, and invasion of PC-3 prostate cancer cells. Cancer Lett. 2015;369(1):103-11.

25. Min J, Huang K, Tang H, Ding X, Qi C, Qin X, et al. Phloretin induces apoptosis of non-small cell lung carcinoma A549 cells via JNK1/2 and p38 MAPK pathways. Oncol Rep. 2015;34(6):2871-9.

26. Nuutila AM, Puupponen-Pimia $R$, Aarni M, Oksman-Caldentey KM. Comparison of antioxidant activities of onion and garlic extracts by inhibition of lipid peroxidation and radical scavenging activity. Food Chem. 2003;81(4):485-93.

27. Kostic DA, Dimitrijevic DS, Mitic SS, Mitic MN, Stojanovic GS, Zivanovic AV. A survey on macro- and micro-elements, phenolic compounds, biological activity and use of Morus spp. (Moraceae). Fruits 2013;68(4):333-47.

28. Dimitrova MP, Petkova NT, Denev PP, Aleksieva IN. Carbohydrate composition and antioxidant activity of certain Morus species. IJPPR 2015;7(3):621-7.

29. Galati G, O'Brien PJ. Potential toxicity of flavonoids and other dietary phenolics: Significance for their chemopreventive and anticancer properties. Free Radic Biol Med. 2004;37(3):287-303.

30. Liu M, Li XQ, Weber C, Lee CY, Brown J, Liu RH. Antioxidant and antiproliferative activities of raspberries. J Agric Food Chem. 2002;50:2926-30.

31. Skupien K, Kostrzewa-Nowak D, Oszmianski J, Tarasiuk J. In vitro antileukaemic activity of extracts from chokeberry (Aronia melanocarpa [Michx] Elliott) and mulberry (Morus alba L.) leaves against sensitive and multidrug resistant HL60 cells. Phytother Res. 2008;22(5):689-94.

32. Dat NT, Binh PT, Quynh le TP, Van Minh C, Huong HT, Lee JJ. Cytotoxic prenylated flavonoids from Morus alba. Fitoterapia 2010;81:1224-7.

33. Jing P, Bomser JA, Schwartz SJ, He J, Magnuson BA, Giusti MM. Structurefunction relationships of anthocyanins from various anthocyanin-rich extracts on the inhibition of colon cancer cell growth. J Agric Food Chem. 2008;56(20):9391-8.

34. Diaz-Moralli S, Tarrado-Castellarnau M, Miranda A, Cascante M. Targeting cell cycle regulation in cancer therapy. Pharmacol Ther. 2013;138:255-71.
35. Nguyen V, Tang J, Oroudjev E, Lee CJ, Marasigan C, Wilson L, et al. Cytotoxic effects of bilberry extract on MCF7-GFP-tubulin breast cancer cells. J Med Food. 2010;13(2):278-85.

36. Kollar P, Barta T, Hosek J, Soucek K, Zavalova VM, Artinian S, et al. Prenylated flavonoids from Morus alba $L$. cause inhibition of $G_{1} / S$ transition in THP-1 human leukemia cells and prevent the lipopolysaccharide-induced inflammatory response. Evid Based Complement Alternat Med. 2013; Article ID: 350519 , doi: 10.1155/2013/350519.

37. Lopez J, Tait SWG. Mitochondrial apoptosis: Killing cancer using the enemy within. Br J Cancer 2015;112(6):957-62.

38. Deepa M, Sureshkumar T, Satheeshkumar PK, Priya S. Purified mulberry leaf lectin (MLL) induces apoptosis and cell cycle arrest in human breast cancer and colon cancer cells. Chem Biol Interact. 2012;200(1):38-44.

39. Fulda S, Galluzzi L, Kroemer G. Targeting mitochondria for cancer therapy. Nat Rev Drug Discov. 2010;9(6):447-64.

40. Lee JC, Won SJ, Chao CL, Wu FL, Liu HS, Ling P, et al. Morusin induces apoptosis and suppresses NF-kappaB activity in human colorectal cancer HT-29 cells. Biochem Biophys Res Commun. 2008; 372(1): 236-42.

41. Faria A, Pestana D, Teixeira D, de Freitas V, Mateus N, Calhau C. Blueberry anthocyanins and pyruvic acid adducts: Anticancer properties in breast cancer cell lines. Phytother Res. 2010;24(12):1862-9.

42. Kikuchi T, Nihei M, Nagai H, Fukushi H, Tabata K, Suzuki T, et al. Albanol A from the root bark of Morus alba L. induces apoptotic cell death in HL60 human leukemia cell line. Chem Pharm Bull. 2010;58(4):568-71.

43. Zhang X, Chen M, Zou P, Kanchana K, Weng Q, Chen W, et al.: Curcumin analog WZ35 induced cell death via ROS-dependent ER stress and G2/M cell cycle arrest in human prostate cancer cells. BMC Cancer 2015;15(1):866.

44. Jeong JC, Jang SW, Kim TH, Kwon CH, Kim YK. Mulberry fruit (Morus fructus) extracts induce human glioma cell death in vitro through ROSdependent mitochondrial pathway and inhibits glioma tumor growth in vivo. Nutr Cancer 2010;62(3):402-12.

\section{SUMMARY}

- Morus rubra extract has had good antioxidant properties according to total phenolic content and reducing power analysis.

- Seven compounds have been determined in the extract and gallic acid is the most abundant compound.

- Extract has exhibited moderate selective cytotoxic effect against human lung and prostate cancer cells compared to human normal fibroblast cells.

- Extract has increased cell cycle arrest at G1 phase and exhibited apoptotic features via decreasing mitochondrial membrane potential in both prostate and lung cancer cells.

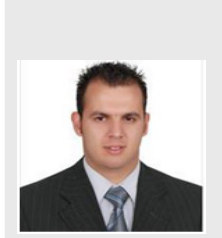

\section{About Authors}

Ibrahim Turan is presently working as Assistant Professor in Department of Genetic and Bioengineering in Gumushane University. At the same time he is also working as a manager in the Medicinal Plants, Traditional Medicine Practice and Research Center in Gumushane University. He has experience in the area of pharmaceutical chemistry, genetics, cancer, molecular biology and biochemistry. He has published a number of papers in his expertise area in various journals.

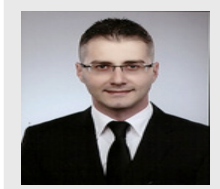

Selim Demir is presently working as Assistant Professor in Department of Nutrition and Dietetics in Karadeniz Technical University. He has experience in the area of pharmaceutical chemistry, cell culture, cancer, and molecular biochemistry.

Cite this article: Turan I, Demir S, Kilinc K, Aliyazicioglu Y, Alver A, Misir S, Yaman SO, Akbulut K, Mentese A, Deger O. Morus rubra Extract Induces G1 Cell Cycle Arrest and Apoptosis in Human Lung and Prostate Cancer Cells. Indian J of Pharmaceutical Education and Research. 2017;51(1):51-8. 